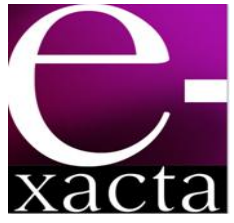

ISSN: 1984-3151

\section{ARQUITETURA DE TERRA: ALTERNATIVA SUSTENTÁVEL PARA OS IMPACTOS AMBIENTAIS CAUSADOS PELA CONSTRUÇÃO CIVIL}

\author{
EARTH ARCHITECTURE: ALTERNATIVE FOR SUSTAINABLE \\ ENVIRONMENTAL IMPACTS CAUSED BY CONSTRUCTION
}

1 Graduandos em Engenharia Ambiental. Centro Universitário de Belo Horizonte - UNIBH. Belo Horizonte, MG. mayra vitor@hotmail.com.

2 Mestre em Geografia. UFMG, 1997. Professora do Centro Universitário de Belo Horizonte - UNIBH. Belo Horizonte, MG. marcia.marques@prof.unibh.br.

Recebido em: 21/09/2014 - Aprovado em: 22/05/2015 - Disponibilizado em: 30/05/2015

RESUMO: A construção civil é uma das maiores contribuintes para a crise ambiental no mundo. No ciclo de vida das construções em geral, são considerados: a produção dos materiais, a sua construção, seu uso, demolição e reciclagem ou gerenciamento dos resíduos. Verificando os aspectos ambientais envolvidos nos processos construtivos seria possível entender os impactos gerados e assim inserir um projeto nas decisões relativas à gestão ambiental da obra. Visando ao entendimento dos impactos ambientais, neste trabalho foi utilizada a análise da construção civil para a comparação de recursos naturais utilizados, entre eles cimento, cerâmica e ferro, visando encontrar alguns problemas gerados por suas produções e propor uma nova alternativa, sendo esta a arquitetura de terra. No Brasil a arquitetura de terra é uma técnica utilizada de forma pontual, essencialmente no período colonial. Ela vem sendo buscada novamente na atualidade como uma alternativa para aprimorar a ideia de sustentabilidade.

PalavRAS-Chave: Construção Civil. Crise Ambiental. Ciclo de Vida. Arquitetura de Terra. Período Colonial.

ABSTRACT: The construction industry is one of the largest contributors to the environmental crisis in the world. In the life cycle of buildings in general are considered: the production of materials, its construction, its use, demolition and recycling or waste management. Checking the environmental aspects involved in construction processes would be possible to understand the impacts generated and thus enter a project in decisions concerning the environmental management of the work. Toward an understanding of the environmental impacts of this study was used to analyze the building to compare natural resources used including cement, ceramic and iron, aiming to find some problems generated by their production and propose a new alternative, which is the architecture earth. In Brazil, the land of architecture is a technique used in a timely manner, essentially in the colonial period. She has been sought again today as an alternative to enhance the idea of sustainability.

KEYWORDS: Civil Construction. Environmental Crisis. Life Cycle. Earth Architecture. Colonial Period.

\section{INTRODUÇÃo}

Um dos mais importantes setores da economia é a construção civil, essencial para o desenvolvimento e responsável, no país, por mais de 2,327 milhões de empregos diretos e indiretos, de acordo com pesquisa do SindusCon-SP - Sindicato da Indústria 
da Construção Civil do Estado de São Paulo (DIVISI ENGENHARIA, 2010). De acordo com a mesma pesquisa, em contrapartida, o setor se caracteriza como um dos que mais utiliza recursos naturais, desde a produção dos insumos utilizados até a execução da obra e sua operação. No Brasil, $75 \%$ do que é extraído para a construção civil advém do meio natural.

Com os impactos causados pela produção dos materiais da construção civil (ferro, cerâmica, cimento) e seu transporte, o presente trabalho traz o conceito de arquitetura de terra como uma opção para reduzir esses impactos, devido à possibilidade de diminuição de gastos com material e frota de caminhões, substituindo materiais que podem ser elaborados da própria terra.

A arquitetura de terra é uma técnica antiga usada pelo homem, que compreende a construção com a terra crua. No Brasil essa técnica construtiva foi trazida pela colonização portuguesa, que utilizava muitas construções com adobe e taipa de pilão. Desde então vem sendo utilizada, tornando-se recentemente uma alternativa condizente com 0 conceito de sustentabilidade, oferecendo ainda vantagens como conforto térmico, regulação da umidade do ar e redução da produção de resíduos químicos.

Duarte (2010) salienta que a terra utilizada nesta técnica equivale ao solo, que resulta da decomposição de rochas, elementos minerais e orgânicos.

No mundo esta tecnologia já é bem utilizada em países como Alemanha, Espanha, Chile, Oriente Médio e China. Apesar de ser muito difundida nos séculos anteriores no Brasil colonial, hoje é pouco utilizada.

O preconceito quanto a esta arquitetura se dá por falta de informação, uma vez que ela é considerada ultrapassada e alguns a correlacionam à pobreza e doença de chagas, já que a proliferação da doença ocorreu em porções do interior, onde predominam construções coloniais. Estudos recentes consideram que o vetor da doença, o barbeiro, adentra essas residências devido à expulsão da sua fonte de alimento, o sangue dos tatus, que por sua vez se afastam da região devido ao desmatamento (UFSC, 2004).

Percebe-se que as técnicas de construção com terra possuem características que compreendem as condições de sustentabilidade; apresentam custo de montagem e manutenção baixo, o que permite o seu consumo pela população local; utilizam matéria prima in situ sem exigir transporte, a qual, por sua vez, consome energia ou recursos não renováveis, e os materiais utilizados são reciclados, ou seja, não geram resíduos e utilizam em sua produção mão-de-obra local.

Neste contexto, a arquitetura de terra é uma técnica viável, uma vez que pode atenuar uma grande quantidade de impactos ambientais que o processo da construção civil causa ao meio ambiente, sendo uma solução que deve ser retomada em projetos sustentáveis.

O objetivo deste trabalho é produzir um estudo acerca dos principais impactos ambientais gerados pela cadeia produtiva dos materiais básicos utilizados na construção civil, propondo a arquitetura de terra como um dos meios alternativos ao padrão adotado neste setor.

\section{Metodologia}

A metodologia do presente trabalho parte de uma abordagem interdisciplinar, na qual foram analisados aspectos referentes a diferentes áreas do conhecimento, buscando a integração de questões que envolvem o sistema produtivo analisado. Parte 
de uma análise dos impactos causados pela construção civil com o uso de seus materiais convencionais, propondo como alternativa de minimização desses impactos por meio da utilização da técnica de arquitetura de terra.

Com o propósito de demonstrar que a arquitetura pode ser útil, foram analisados os preceitos da topografia sustentável, na qual a terra retirada no terreno deve ser aproveitada suficientemente. Neste sentido foi pesquisado como a retirada da terra pode ser aproveitada e em que quantidade poderá ser viável no processo.

Buscou-se apresentar a viabilidade de atenuação sonora - que é a perda gradual de intensidade de propagação do som ou onda sonora do material. Essa viabilidade foi comprovada através da comparação acústica do bloco ecológico ${ }^{1}$ com 0 bloco convencional, sendo fundamentada a partir de estudos de amenização dos ruídos proferidos em diferentes tipos de ambientes estruturais, tais como bloco convencional cerâmico e bloco ecológico.

Para quantificar os impactos da construção civil foi utilizada uma função probabilística, com o objetivo de avaliar os impactos causados pelos principais materiais da construção civil (cimento, ferro e cerâmica). Por meio dessa função é possível criar inferências que poderão especificar o quanto será produzido de $\mathrm{CO}_{2}$, caso a utilização dos materiais permaneça no mesmo progresso de consumo das gerações atuais.

Diante do exposto, avaliou-se pertinente a utilização do programa SCILAB 5.3.3, um programa que viabiliza o cálculo de regressão linear e outros cálculos utilizando algoritmos. Os dados que

\footnotetext{
${ }^{1}$ Bloco Ecológico: Parede de tijolos de solocimento de aproximadamente $150 \mathrm{~mm} \times 300 \mathrm{~mm}$ $x 75 \mathrm{~mm}$, assentado com juntas amarradas.
}

alimentaram o programa foram obtidos através de estudos bibliográficos de emissão de $\mathrm{CO}_{2}$ dos últimos anos, com objetivo de criar gráficos a partir da regressão linear e com isso verificar as emissões de $\mathrm{CO}_{2}$. Desta forma torna-se possível realizar análises, assim como avaliar quais serão os picos máximos de emissão de $\mathrm{CO}_{2}$ do ano estudado e apresentar dados de emissão de dióxido de carbono para os próximos anos.

Foram inseridos os dados das tabelas 2, 3 e 4 na seguinte disposição no programa SCILAB:

clc; $\quad$ clear; $\quad x(01)=A n o ; \quad x(02)=A n o ; \quad x(03)=A n o$; $x(04)=A n o ; \quad x(05)=A n o ; \quad x(06)=A n o ; \quad x(07)=A n o$; $x(08)=$ Ano; $x(09)=A n o ; x(10)=A n o ; x(11)=$ Ano;

$y(01)=$ Quantidade de CO2 emitido em toneladas; $y(02)=$ Quantidade de CO2 emitido em toneladas; $y(03)=$ Quantidade de CO2 emitido em toneladas; $y(04)=$ Quantidade de CO2 emitido em toneladas; $y(05)=$ Quantidade de CO2 emitido em toneladas; $y(06)=$ Quantidade de CO2 emitido em toneladas; $y(07)=$ Quantidade de CO2 emitido em toneladas; $y(08)=$ Quantidade de CO2 emitido em toneladas; $y(09)=$ Quantidade de CO2 emitido em toneladas; $y(10)=$ Quantidade de CO2 emitido em toneladas; $y(11)=$ Quantidade de CO2 emitido em toneladas; coefs $=$ regress $(x, y)$; printf ("In inclinação vale: $\% .5 f ", \operatorname{coefs}(2)$ ); printf ("In coeficiente linear vale: $\% .5 f ", \operatorname{coefs}(1))$; plot $(x, y)$;

\section{IMPACTOS DA CONSTRUÇÃO CIVIL}

Ferreira et al. (2009) afirmam que a construção civil possui relevante impacto no meio ambiente e requer um gasto energético elevado. Além de tudo, os resíduos gerados da atividade não têm uma destinação correta, mesmo que a legislação em vigor exija. A utilização de recursos em grande quantidade acaba por promover perdas por falhas e omissões nos projetos e até na execução, produzindo resíduos. 
A construção civil é designada como uma das principais atividades para a progressão social e econômica dos países, e antagonicamente apresenta impactos ambientais significativos que perpassam 0 consumo de recursos naturais, a geração de resíduos, além da modificação da paisagem natural (PINTO, 2005).

A cadeia produtiva da construção civil, segundo Costa (2007), é responsável por aproximadamente $40 \%$ da formação bruta de capital do país, empregando consequentemente um relevante número de trabalhadores.

Estudos indicam que o setor consome demasiada quantidade de materiais com significativo teor energético, como aço, cimento, alumínio, cerâmica, entre outros materiais que precisam ser transportados. Estima-se ainda que $80 \%$ da energia é consumida no transporte dos materiais da construção civil (JOHN, 2001, apud COSTA, 2007). Para este autor, qualquer sociedade preocupada deve colocar a sustentabilidade como prioridade no aperfeiçoamento da construção civil.

Os materiais cerâmicos são produzidos a partir da argila, conhecida popularmente como barro. A argila é um minério extraído de uma jazida. É um material sedimentar, fino, derivado de rochas com presença de silicatos de alumínio hidratados. (ECOCASA, 2011)

Segundo dados da Anfacer (2001, apud ROSA, e PEIXOTO, 2003), o Brasil é o segundo maior consumidor mundial de revestimentos cerâmicos. Possui cerca de 130 unidades industriais, sendo que em sua maior parte são empresas de médio porte e controladas por capital privado e nacional. Atualmente, $9,8 \%$ da produção nacional são exportados. O setor é responsável pela geração de 27 mil empregos diretos e aproximadamente 287 mil indiretos. De acordo com o mesmo autor, o país ocupa ainda a quarta posição entre os maiores produtores de cerâmica, demonstrado em 2001 uma produção 474 milhões de $\mathrm{m}^{2}$, perdendo para os seguintes países: Espanha, Itália e China.

Durante a produção da cerâmica, há consumo de energia térmica e elétrica, geram-se emissões de $\mathrm{CO}_{2}$ e consumo de água. Para diminuir os impactos ambientais associados, deve-se recorrer a planos de gestão ambiental, visando a minimizá-los (ECOCASA, 2011).

Loyola (2010) salienta que o principal problema deste sistema produtivo é a degradação de áreas causada pela extração de argila ilegal e seu posterior abandono após o esgotamento da jazida. Segundo o autor a extração ilegal é um fator agravante devido à mão de obra não qualificada para uma boa lavra.

A transformação do minério de ferro em aço é realizada a partir da indústria siderúrgica, de maneira que o minério possa ser usado comercialmente. Este processo denomina-se Redução. Inicialmente, o minério - cuja procedência básica é o óxido de ferro $(\mathrm{FeO})$ - é aquecido em fornos especiais conhecidos como altos fornos, em presença de carbono (sob a forma de coque ou carvão vegetal) e de fundentes que são adicionados para auxiliar a produzir a escória, que, por sua vez, é formada de materiais indesejáveis ao processo de fabricação. $O$ objetivo desta primeira etapa é reduzir ao máximo o teor de oxigênio da composição FeO. A partir disso, obtémse o ferro-gusa. O aço, por fim, será o resultado da descarbonatação do ferro gusa, ou seja, é produzido a partir deste, controlando-se o teor de carbono para no máximo $2 \%$. A partir desse processo forma-se então uma liga metálica constituída basicamente de ferro e carbono (FERRAZ, 2003).

De acordo com Coelho (2007 apud MILANEZ; PORTO, 2008), a produção siderúrgica nacional, em sua maior parte, foi conduzida para o setor 
domiciliar. Entre os principais consumidores de aço, destacam-se a construção civil (29\%), o setor automotivo (28\%) e os produtores de bens capitais (21\%).

A mineração é um setor da economia que colabora de forma relevante para a melhoria da qualidade de presentes e futuras gerações, sendo essencial para o desenvolvimento de uma sociedade, desde que seja procedida com responsabilidade social e de acordo com os preceitos da sustentabilidade (FARIAS, 2002).

Entre os impactos gerados pela mineração de ferro, destacam-se a construção de barragens para a geração de hidroeletricidade que movimentará o maquinário pesado, o uso não controlado de água subterrânea, a desconfiguração do relevo, dentre outros.

No Brasil, os principais problemas oriundos desta extração podem ser inseridos em quatro categorias: poluição da água, poluição do ar, poluição sonora, e subsidência do terreno.

Em geral, a mineração provoca um conjunto de efeitos não desejados, que podem ser denominados externalidades. Algumas dessas externalidades são: alterações ambientais, conflitos de uso do solo, depreciação de imóveis circunvizinhos, geração de áreas degradadas e transtornos ao tráfego urbano (FARIAS, 2002).

O setor siderúrgico provoca grandes impactos de poluição atmosférica. Emite uma série de óxidos de enxofre (SOx), gás sulfídrico (H2S), óxidos de nitrogênio (NOx), monóxido de carbono (CO), dióxido de carbono (CO2), metano $(\mathrm{CH} 4)$, etano $(\mathrm{C} 2 \mathrm{H} 6)$, material particulado e diferentes hidrocarbonetos orgânicos, como o benzeno. Ressaltando que o $\mathrm{CO} 2$ e $\mathrm{CH} 4$ contribuem para o aumento da quantidade de carbono na atmosfera e, resultando em mudanças climáticas. (MILANEZ; PORTO, 2008)
Segundo o Instituto Observatório Social (2011) a cadeia produtiva do ferro gusa no Estado do Pará é uma das que mais devasta o meio ambiente. Calcula-se que são desmatados anualmente até cinco milhões de metros cúbicos de florestas nativas no estado para a produção de carvão vegetal. A produção de uma tonelada de ferro-gusa requer 875 $\mathrm{kg}$ de carvão vegetal. Para se chegar a essa quantidade, são necessários 2,6 mil kg de madeira seca (que, em média tem uma densidade de 306 $\mathrm{kg} / \mathrm{m}^{3}$ em matas nativas). Ou seja, esta matériaprima necessita o desmatamento de uma área de pelo menos 600 metros quadrados.

O cimento mais utilizado atualmente, conhecido como cimento Portland, é um material cerâmico composto basicamente de calcário e argila que em contato com outros materiais, como a água forma o concreto (AMDA, 2011).

Radicchi (2002) salienta que o principal material para construção e segundo produto mais vendido no mundo é o cimento. Mas a utilização desse material gera um grande impacto ambiental em todo seu ciclo de vida. A indústria de cimento é responsável por 7 \% de emissão de gás carbônico na atmosfera, só no Brasil são lançados 22,8 milhões de toneladas por ano.

Os impactos ambientais gerados pela produção do cimento começam na sua extração, no processo de mineração da rocha calcária. Essa atividade prejudica não só o relevo local, mas também todo aquele ecossistema que depende desse tipo de rocha para sobreviver, como as matas secas que se localizam no topo desses paredões de calcário, ressaltando que este minério é um recurso natural finito. No transporte do cimento, que é feito tanto por caminhões como por correias transportadoras a poluição é eminente, pois essas máquinas consomem quantidades elevadas de combustíveis 
fosseis como: gasolina e óleo diesel. A queima desse material libera o gás carbônico que é um dos principais causadores do efeito estufa (AMDA, 2011).

A poeira gerada no processo de extração também é relevante, podendo prejudicar os trabalhadores e também 0 meio biótico nas proximidades da mineração.

De acordo com a AMDA (2011) na produção cimentícia são encontrados alguns impactos, dos quais são descritos:

1. Extração do calcário - alteração do relevo; possíveis erosões; perda de patrimônio arqueológico e espeleológico; danos à flora, fauna e recursos hídricos; gasto de combustíveis fósseis; produção de resíduos; emissão de gases causadores do Efeito Estufa.

2. Industrialização - gasto de recursos naturais diversos e de quantidade exorbitante de energia elétrica; geração de efluentes líquidos e gasosos e geração de resíduos sólidos; gasto de combustíveis fósseis e alta emissão de gases causadores do Efeito Estufa.

3. Embalagem e transporte - gasto indireto (fabricação de veículos) e direto de recursos naturais (queima de combustíveis fósseis - gasolina, óleo diesel, graxas), emissão de gases causadores de Efeito Estufa; geração de resíduos sólidos.

4. Consumo - geração de resíduos (embalagens feitas de papel que são recicláveis e entulhos restantes de obras ou demolições também recicláveis).

Auxiliadora e Arsênio (2004) relatam que em todas as suas etapas do processo: moagem e homogeneização das matérias primas; clinquerização no forno e resfriamento do clinquer (como é denominado o material após sair do forno); moagem do clínquer; adições e produção de cimento; ensacamento e expedição do produto - há poluição.

Segundo o Código de Regulamentação Federal de Proteção ao Meio ambiente dos Estados Unidos de 1991, assim como a Agência de Proteção Ambiental do mesmo país de 1996 (apud AUXILIADORA; ARSÊNIO, 2004), as empresas de fabricação de cimento estão entre as maiores fontes de emissão de poluentes atmosféricos perigosos, dentre os quais destacam-se: dioxinas e furanos; os metais tóxicos como mercúrio, chumbo, cádmio, arsênio, antimônio e cromo; os produtos de combustão incompleta e os ácidos halogenados.

\section{Arquitetura de terra como Alternativa}

A arquitetura de terra data de 9000 anos, uma vez que as culturas antigas usaram essa técnica em suas construções. No Turcomenistão foram encontradas casas construídas com terra do período de 8000 a 6000 a.C.; no Egito as construções com adobe apresentam mais de 3000 anos. A Grande Muralha da China é uma construção de terra muito antiga, na qual foram usadas taipas enchapadas com pedras naturais e ladrilhos, o que fez com se que parecesse com uma construção de pedra. No México, o centro da pirâmide do Sol é constituído por 2 milhões de toneladas de terra pisada e foi construída entre os anos 300 e 900 d.C. (UFSC, 2004).

O maior desafio para o uso das construções em terra é puramente subjetivo, pois se trata do preconceito generalizado que associa as obras de prestígio às técnicas e materiais modernos, considerando a arquitetura de terra como precária e símbolo de baixo status social (IGLESSIAS, 1993 apud LOPES; INO, 2003). 
Nas últimas décadas, a utilização desta técnica foi reduzida devido ao surgimento de matérias que tornam o processo construtivo mais rápido - apesar de devastador. Pode-se notar, nos últimos anos, um crescente interesse por construções ambientalmente sustentáveis, assim como a necessidade de minimizar o déficit habitacional em todo o mundo. Deste modo as técnicas de construção com terra vêm sendo resgatadas. (BORGES; COLOMBO, 2009).

Maia et al. (2008) propõem materiais considerados alternativos e mais sustentáveis, tais como o adobe (bloco de terra crua), o tijolo ecológico (solo-cimento) e taipa de mão (pau a pique), que são utilizados como vedação por motivos que variam desde o reduzido impacto ambiental até como à tendência do mercado na busca de materiais com apelo ecológico - a demanda tem se modificado. Entretanto, a escolha sem prévia análise da viabilidade técnica e das condições de execução destas opções pode resultar em custos e problemas maiores do que com o uso de materiais convencionais.

Oliveira (2005) salienta que o adobe é um material de construção usado milenarmente em diversas partes do mundo, sendo, portanto, um material tradicional. Além disso, os insumos necessários para a sua produção (terra, fibra natural e água) podem ser encontrados localmente; a energia utilizada em sua manufatura é quase nula; e a mão de obra empregada pode ter pouca especialização, tornando o adobe um material apropriado do ponto de vista da sustentabilidade. Sendo assim, a pesquisa e o desenvolvimento dessa técnica de construção poderão contribuir para que sua aplicação possa ser sistematizada, e o seu uso, resgatado.

\section{Resultados e discussão}

De acordo com Alvarenga (2009), o número de andares de uma construção utilizando a arquitetura de terra não tem limites, o importante é uma técnica bem executada. Há casos como a construção de uma escola em Contagem em Minas Gerais, como mostra a FIG. 1, com cinco pavimentos usando a alvenaria armada, ou seja, uma alvenaria utilizada em edificações que dispensa estruturas convencionais, como vigas e pilares.

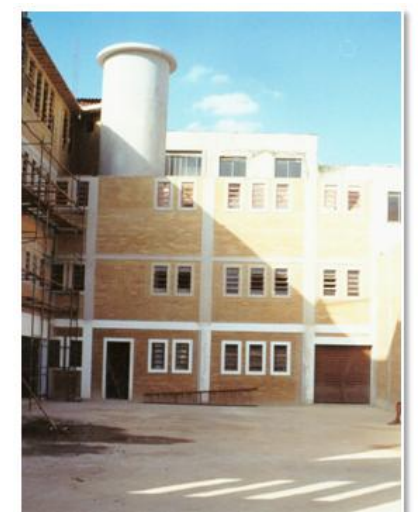

Figura 1 - Escola em Contagem-MG, Brasil. Fonte: Alvarenga (2011).

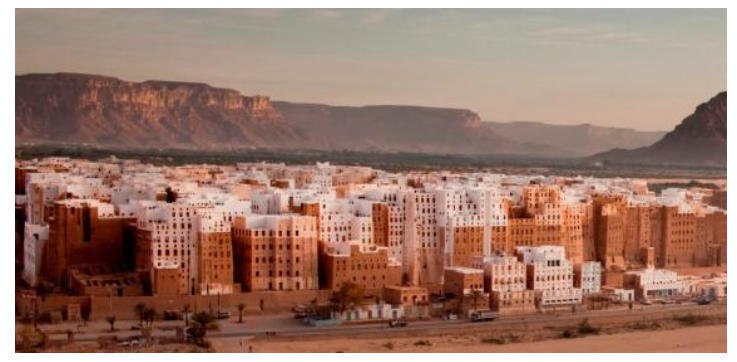

Figura 2 - Shibam, no lêmen. Fonte: panoramio.com.

Em Shibam, cidade do lêmen próxima à Arábia Saudita, existem prédios de terra que chegam a 18 andares, com taipa de pilão e adobe (FIG. 2). 
Na Alemanha há uma construção de dez andares feita de pau-a-pique (FIG. 3).

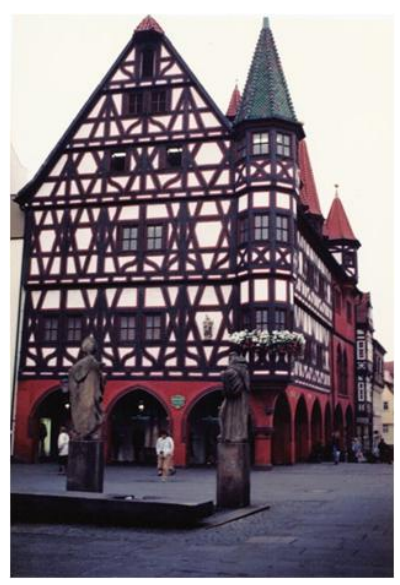

Figura 3 - Construção na Alemanha.

Fonte: Alvarenga (2011).

Segundo o mesmo autor, para a produção de 1000 blocos ecológicos, gastam-se $1,0 \mathrm{~m}^{3}$ de terra, 4 sacos de cimento e $0,25 \mathrm{~m}^{3}$ de areia. E para cada $1,0 \mathrm{~m}^{2}$ de alvenaria utilizam-se 64 blocos.

A arquitetura de terra suporta construções de grande porte, mas, dependendo da quantidade de terra a ser retirada, recomenda-se apenas a pequenas construções, partindo da adoção do método do assentamento, que compreende o aproveitamento da terra que é retirada do talude de corte e inserida no talude de aterro para compensar o terreno.

Quanto à acústica, o conforto gerado em construções utilizando o bloco de solo-cimento é amenizado em 39 decibéis em uma frequência de $500 \mathrm{~Hz}$, comparando a construção com os blocos convencionais que se diferem em média 45 decibéis dependendo da composição.

O teste feito para atenuação sonora foi realizado em uma parede, cujo revestimento consistia em uma mistura de cimento e solo. As dimensões aproximadas da parede foram de $3000 \mathrm{~mm}$ x 4000 $\mathrm{mm} \times 150 \mathrm{~mm}$ e densidade superficial aproximada de
$350 \mathrm{~kg} / \mathrm{m}^{2}$. A área construída total da parede foi de $12 \mathrm{~m}^{2}$

Na TAB. 1 são apresentados os valores de índice de redução sonora para cada faixa de freqüência. Estes mesmos resultados são apresentados no GRÁF. 1, no qual também são apresentados os índices de redução sonora ponderados e os coeficientes de adaptação do espectro, estes últimos calculados conforme a ISO 717 - 1:1996, que define um único número de quantidades para o isolamento do som no ar em edifícios e de elementos de construção, como paredes, pisos, portas e janelas (INSTITUTO DE PESQUISA TECNOLÓGICAS, 2007).

Tabela 1

Índice de redução sonora

\begin{tabular}{||c|c|}
\hline $\begin{array}{c}\text { Frequência do } \\
\text { centro da banda } \\
\text { de terço de oitava } \\
\text { (Hz) }\end{array}$ & $\begin{array}{c}\text { Índice de } \\
\text { redução sonora } \\
(\mathbf{d B})\end{array}$ \\
\hline 100 & 40 \\
\hline 125 & 40 \\
\hline 160 & 37 \\
\hline 200 & 36 \\
\hline 250 & 36 \\
\hline 315 & 36 \\
\hline 400 & 37 \\
\hline 500 & 39 \\
\hline 630 & 42 \\
\hline 800 & 44 \\
\hline 1000 & 47 \\
\hline 1250 & 50 \\
\hline 1600 & 49 \\
\hline 2000 & 51 \\
\hline 2500 & 52 \\
\hline 3150 & 50 \\
\hline 4000 & 48 \\
\hline 5000 & 43 \\
\hline & \\
\hline
\end{tabular}

Fonte: Instituto de Pesquisa Tecnológica - IPT, 2007. 


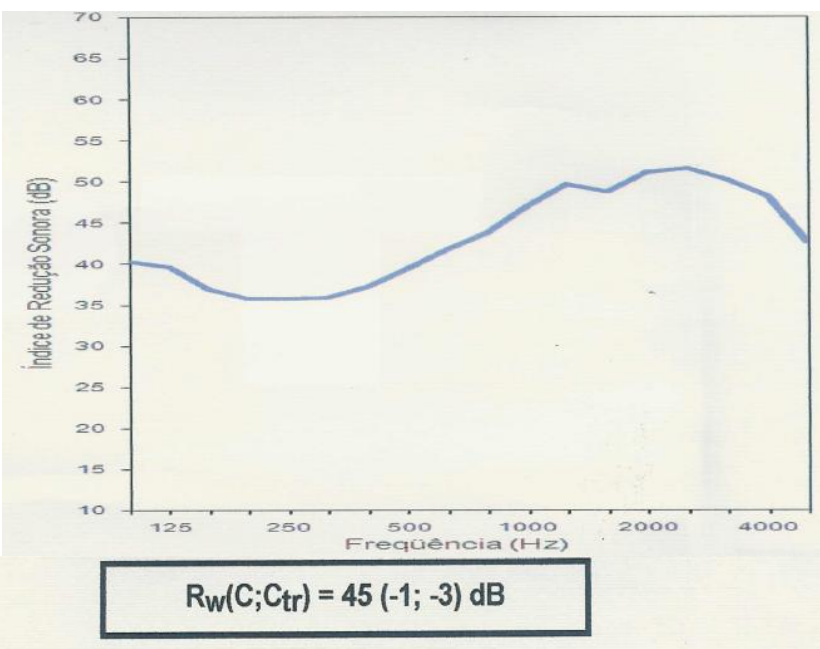

$\mathrm{R}_{\mathrm{W}}=$ Índice de Redução Sonora Ponderado

$C=$ Coeficiente de Adaptação do espectro para Ruído Rosado

$\mathrm{C}_{\text {tr }}=$ Coeficiente de Adaptação do Espectro para Ruído de Trânsito

Gráfico 1 - Índice de redução sonora

Fonte: Instituto de Pesquisa Tecnológica - IPT, 2007.

Consta abaixo, no Quadro 1, a demonstração dos índices de redução sonora do bloco convencional utilizado na construção civil, levando-se em consideração uma frequência de $500 \mathrm{~Hz}$.

\section{Quadro 1}

Atenuação do som de acordo com o tipo de tijolo utilizado

\begin{tabular}{||c|c||}
\hline Material & $\begin{array}{c}\text { Atenuação } \\
\text { (PT) }\end{array}$ \\
\hline \hline $\begin{array}{c}\text { Parede de tijolo maciço com } 45 \mathrm{~cm} \text { de } \\
\text { espessura }\end{array}$ & $55 \mathrm{~dB}$ \\
\hline $\begin{array}{c}\text { Parede de } 1 \text { bloco de espessura de } \\
23 \mathrm{~cm}\end{array}$ & $50 \mathrm{~dB}$ \\
\hline $\begin{array}{c}\text { Parede de meio tijolo de espessura com } \\
12 \mathrm{~cm} \text { e rebocado }\end{array}$ & $45 \mathrm{~dB}$ \\
\hline $\begin{array}{c}\text { Parede de concreto de } 8 \mathrm{~cm} \text { de } \\
\text { espessura }\end{array}$ & $40 \mathrm{~dB}$ \\
\hline $\begin{array}{c}\text { Parede de tijolo vazado de } 6 \mathrm{~cm} \text { de } \\
\text { espessura e rebocado }\end{array}$ & $35 \mathrm{~dB}$ \\
\hline
\end{tabular}

Fonte: Fernandez (1994).

Utilizaram-se os dados das TAB. 2, 3 e 4, com o objetivo de criar os gráficos com projeções de $\mathrm{CO}_{2}$ para os próximos anos, acerca dos dados bibliográficos do artigo de Almeida et al. (2007).

Tabela 2

TELHAS E ACESSÓRIOS (madeira, ferragem, pregos, parafusos, barras.). Em toneladas de $\mathrm{CO}_{2}$

\begin{tabular}{cc}
\hline & emitidos \\
\hline Ano & Emissão de $\mathrm{CO}_{2}$ Abrangida \\
\hline 1990 & 68314 \\
1997 & 85530 \\
1998 & 78525 \\
1999 & 79013 \\
2000 & 90689 \\
2001 & 102388 \\
2002 & 106707 \\
2005 & 89436 \\
2006 & $\mathbf{8 0 2 7 5}$ \\
2007 & $\mathbf{7 5 9 2 9}$ \\
2012 & 109244 \\
\hline
\end{tabular}

Fonte - Almeida et al. (2007).

Tabela 3

TIJOLO E ABOBADILHA (abóboda de tijolo e concreto). Em toneladas de $\mathrm{CO}_{2}$ emitidos.

\begin{tabular}{lc}
\hline Ano & Emissão de $\mathrm{CO}_{2}$ Abrangida \\
\hline 1990 & 398752 \\
1997 & 655510 \\
1998 & 673676 \\
1999 & 628206 \\
2000 & 541675 \\
2001 & 509289 \\
2002 & 466624 \\
2005 & 385540 \\
2006 & 344418 \\
2007 & 348746 \\
2012 & 500789 \\
\hline
\end{tabular}

Fonte: Almeida et al. (2007). 
Tabela 4

PAVIMENTO (Concreto e Piso) / REVESTIMENTO (Chapisco, Emboço, Reboco). Em toneladas de $\mathrm{CO}_{2}$ emitidos.

\begin{tabular}{lc}
\hline Ano & Emissão de $\mathrm{CO}_{2}$ Abrangida \\
\hline 1990 & 166845 \\
1997 & 261103 \\
1998 & 282124 \\
1999 & 278148 \\
2000 & 281310 \\
2001 & 270793 \\
2002 & 278850 \\
2005 & 305599 \\
2006 & 306448 \\
2007 & 322172 \\
2012 & 402493 \\
\hline
\end{tabular}

Fonte: Almeida et al. (2007).

Nos dados verificados, viu-se que, para Telha e Acessórios, a inclinação obteve valor de 1206,37651 e Coeficiente linear no valor de -2326794,68799, conforme consta no GRAF. 2:

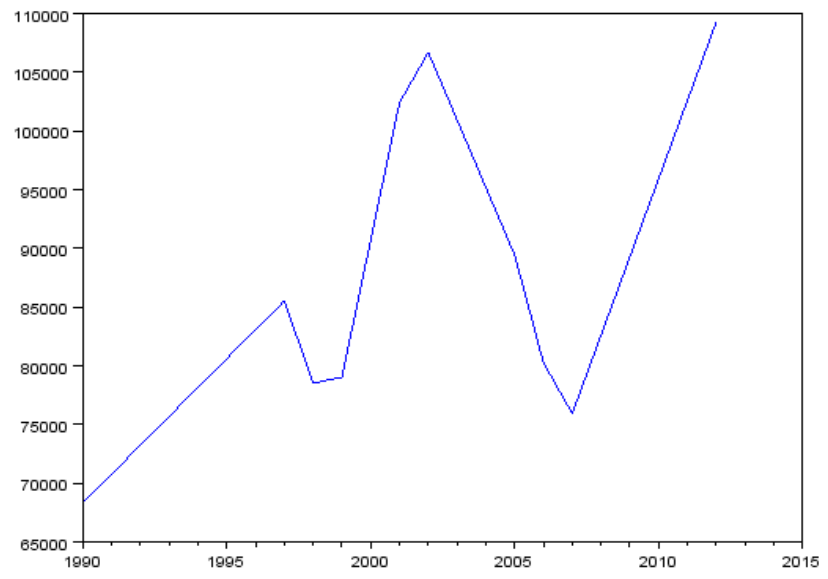

Gráfico 2 - TELHAS E ACESSÓRIOS

Fonte: Almeida et al. (2007).

Para Tijolo e Abobadilha a inclinação obteve valor de 7123,42108 e Coeficiente linear no valor de 14753598,81122, como mostra o GRAF. 3.

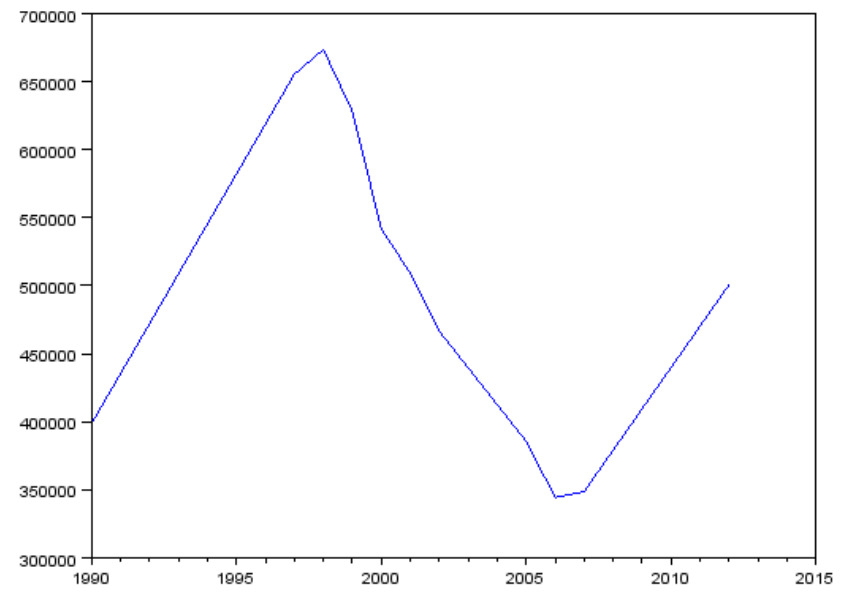

Gráfico 3 - TIJOLO E ABOBADILHA Fonte: Almeida et al. (2007).

Para Pavimento e Revestimento a inclinação obteve valor de 8966,30991 e Coeficiente linear no valor de 17659578,20975, conforme registrado no GRÁF. 4.

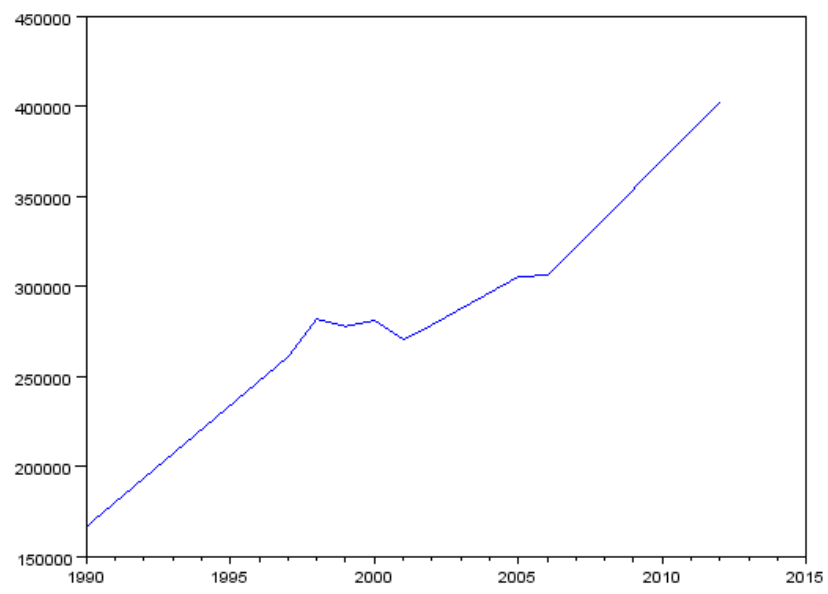

Gráfico 4 - PAVIMENTO e REVESTIMENTO Fonte: Almeida et al. (2007).

Percebe-se com isso que somando os dados encontrados, tem-se a seguinte equação: $Y=5.232 .774,077 X+3.049,2653$. Com isso vê-se que a tendência de o gráfico chegar a zero é dificultosa.

A arquitetura de terra utiliza recursos naturais que por sua vez não emitem $\mathrm{CO}_{2}$. Isso ocorre por não necessitar da queima dos blocos e por utilizar pouco 
cimento, fazendo com que essa seja uma forma de amenizar a emissão de poluentes na atmosfera.

\section{ConClusõES}

De acordo com os estudos realizados, a arquitetura de terra é uma técnica construtiva que pode ser considerada viável, já que influencia de forma positiva na economia, preservação, reutilização e principalmente na criação de projetos sustentáveis. A terra é o material de construção natural mais importante e abundante na maioria das regiões do mundo.

A desmedida exploração, assim como o transporte dos recursos naturais utilizados na construção civil (ferro, cerâmica, cimento) geram desperdícios e também contaminam o meio ambiente. $A$ arquitetura de terra reduz esses impactos devido à diminuição de gastos com material, entre outros, utilizando como recurso a própria terra. $O$ setor da construção civil se caracteriza como um dos que mais utilizam recursos naturais e dos que mais geram desperdícios desnecessários e impactos ao ambiente, desde a produção dos insumos utilizados até a execução da obra e sua operação.

Isso se baseia na ideia da sustentabilidade a arquitetura de terra nada mais é que uma solução que poderá reduzir os impactos ambientais causados pelo maior e mais importante setor da economia, que é a construção civil.

Atualmente, nas grandes construções, há uma considerável retirada de terra que é destinada a aterros de inertes popularmente conhecidos como bota-fora, a qual poderia ser aproveitada na criação de novas construções. Em contraposição, o fato de extrair o solo para criação de tijolos pode ser prejudicial quando a aplicação da técnica de arquitetura de terra é executada em âmbito global. O ideal é que essa técnica seja utilizada pontualmente, ou, no mínimo, que ocorra o assentamento do terreno com o aproveitamento das massas de solo movimentadas, evitando assim a redução do tempo de vida útil dos aterros de inertes e alcançando os objetivos que tangem a sustentabilidade.

O tijolo convencional possui melhor acústica do que o tijolo ecológico, pois a atenuação em uma freqüência de $500 \mathrm{~Hz}$ do tijolo convencional é de 45 $\mathrm{dB}$, e a do tijolo ecológico é de 39dB. Quando o bloco é vazado, a atenuação é menor que a do bloco maciço, levando-se em consideração que o tijolo ecológico estudado é vazado e que a proporcionalidade entre esses dados persiste; se o bloco ecológico não fosse vazado, a atenuação seria maior.

Como visto nos gráficos de emissão de $\mathrm{CO}_{2}$ a tendência é de constante aumento deste gás, podendo chegar a um ponto crítico irreversível. Como a Emissão de $\mathrm{CO}_{2}$ na arquitetura de terra tende a zero, ela pode ser um método para minimizar tal fato.

\section{AGRADECIMENTOS}

Agradecimentos especiais à Maria Auxiliadora Afonso Alvarenga e à Fundação IBI Tecnologia Alternativa, que contribuíram muito para o desenvolvimento da pesquisa. 


\section{REFERÊNCIAS}

ALMEIDA; FRADE; HEITOR. Quantificação de CO2 na indústria cerâmica e estratégias para a sua gestão, Centro Tecnológico da Cerâmica e do Vidro - Apart. 8052 - 3020-053 COIMBRA, Portugal, ano 2007. Disponível em:

<http://www.maotdr.gov.pt/Admin/Files/Documents/Q uantifica\%C3\%A7\%C3\%A30\%20das\%20emiss\%C3 \%B5es\%20de\%20CO2\%20no\%20sector\%20cer\%C3 $\%$ A2mico\%20nacional.pdf>. Acesso em 16 set. 2011.

ALVARENGA, M. A. A., Fundação IBI Tecnologia Alternativa - 2009, Belo Horizonte - MG - Pesquisa interna não publicada

AMDA, Ciclo de Vida do Cimento. Belo Horizonte MG: 2011. Disponível em: $<$ http://www.amda.org.br/detalhe/2,93,3321, ciclo-devida-do-cimento.aspx>. Acesso em 16 set. 2011.

AUXILIADORA, M. M. S.; ARSÊNIO, O. S. F. Combustíveis e riscos ambientais na fabricação do cimento; casos da Região do Calcário ao Norte de Belo Horizonte e possíveis generalizações. Encontro Nacional Anppas. Campinas - SP: 2004. Disponível em:

<http://www.fem.unicamp.br/ seva/anppas04_SantiS eva cimento RMBH.pdf>. Acesso em 03 set. 2011.

BORGES, L. V. dos S.; COLOMBO, C. R. CONSTRUÇÕES COM TERRA: ALTERNATIVA VOLTADA Å SUSTENTABILIDADE - Construções com terra: alternativa voltada à sustentabilidade - 17 de Setembro de 2009. ART_150709.doc. Disponível em: < http://www.blogdoalon.com/ftp/ART_150709.pdf>. Acesso 14 set 2011.

COELHO, C. M. C. S. Os produtos siderúrgicos e o mercado de aço. 2007 apud MILANEZ, B.; PORTO, M. F. S. A ferro e fogo: Impactos da siderurgia para o ambiente e a sociedade após a reestruturação dos anos 1990. Encontro Nacional Anppas . Brasília - DF: 2008. Disponível em: <http://www.anppas.org.br/encontro4/cd/ARQUIVOS/ GT6-61-8-20080509163054.pdf>. Acesso em 28 ago. 2011.

COSTA, M. L. Identificação, caracterização e gestão dos resíduos de madeiras em obras de edificáveis. Dissertação (Mestrado em Gerenciamento e Tecnologias Ambientais no Processo Produtivo) - Universidade Federal da Bahia. Escola Politécnica, - Salvador-BA, 2007. Disponível em: http://www.teclim.ufba.br/site/material_online/disserta coes/dis_maria_livia.pdf . Acesso em $\mathbf{3 0}$ ago. 2011.

DIVISI ENGENHARIA - Engenheiro SILVA, V. da Os verdadeiros impactos da construção civil 2010. Disponível em:

<http://www.divisiengenharia.com.br/site/destaques/o s-verdadeiros-impactos-da-construcao-civil/> Acesso em 14 set. 2011.

DUARTE, F. P. D, Terra crua, Belo Horizonte - MG, Ano 2010. Disponível em: <http://

flavioduarte.webnode.com/mensagens/terra-crua/>. Acesso em 16 nov. 2011.

ECOCASA, Revestimentos de Paredes materiais cerâmicos. 2004. 2p Disponível em:

<http://www.ecocasa.pt/userfiles/file/MATERIAIS\%20 CERAMICOS.pdf>. Acesso 12 set 2011.

FARIAS, C. E. G. Mineração e meio ambiente no Brasil. Relatório preparado para o CGEE- Brasília: 2002. 42p. Disponível em:

<http://www.cgee.org.br/arquivos/estudo011_02.pdf> . Acesso em 05 set. 2011.

FERNANDEZ, J. C. - O Ruído Ambiental: Seus Efeitos e seu Controle - Apostila do Departamento de Engenharia Mecânica da UNESP - Campus de Bauru, 1994. Disponível em: < http://wwwp.feb.unesp.br/jcandido/acustica/Apostila/ Capa.pdf >. Acesso em 28 out. 2011.

FERRAZ, H. O Aço na Construção Civil. São Paulo: Escola de Engenharia de São Carlos da Universidade de São Paulo, 2003. Artigo - Revista Eletrônica de Ciências - Número 22. Disponível em: <http://www.cdcc.usp.br/ciencia/artigos/art_22/aco.ht ml>. Acesso em 18 set. 2011.

FERREIRA, D. D. M. et al.. Gestão de resíduos da construção civil e de demolição: contribuição para a sustentabilidade ambiental, UFSC, V Congresso Nacional de Excelência em Gestão, 2, 3 e 4 de julho de 2009. Disponível em:

<http://www.excelenciaemgestao.org/Portals/2/docu ments/cneg5/anais/T8_0139_0696.pdf>. Acesso em 12 Março. 2015.

INSTITUTO DE PESQUISAS TECNOLÓGICAS Laboratório de conforto ambiental e Sustentabilidade dos Edifícios/ CETAC. São Paulo, 2007. Disponível em: http://www.tijoleco.com.br/img/05_produto/Tijol-Eco_-

Ensaio IPT - Medicao da isolacao sonora.pdf. Acesso em: 28 out. 2011. 
INSTITUTO OBSERVATÓRIO SOCIAL, A Floresta que Virou Cinza. Auditório da Contraf-CUT, São

Paulo: 2011. Disponível em:

<http://issuu.com/observatorio_social/docs/revista_o bservatorio_por>. Acesso em 05 set. 2011

JOHN, V. M. Aproveitamento de resíduos sólidos como materiais de construção. 2001 apud COSTA, M. L. Identificação, caracterização e gestão dos resíduos de madeira em obras de edificação. Salvador - BA, 2007. 182p. Disponível em:

<http://www.teclim.ufba.br/site/material_online/dissert acoes/dis_maria_livia.pdf>. Acesso em 14 set. 2011.

LOPES, W. G. R.; INO A. - Aspectos Construtivos da Taipa de mão - Página 21. Ano 2003. Disponível em: $<$

http://www.habitat.arq.una.py/ambitos/tyh/cct/crh_cct _0087.pdf> Acesso em: 12 Set. 2011.

LOYOLA, L. C. A extração de argila e suas conseqüências. Revista NovaCer, CriciúmaSC,2010. 44p Disponível em:

<http://content.yudu.com/Library/A1nois/RevistaNova Cermaro20/resources/4.htm>. Acesso 14 set 2011.

MAIA R. T. et al.. Análise Comparativa para Escolha de vedação em Terra Crua para o Sistema Estrutural Pilar-Viga em eucalipto.

Estudo de caso: Construção de moradias no Assentamento Rural Sepé- Tiarajú, Serra Azul, SP - Página 21. Ano 2008. São Luís - Maranhão Disponível em: <

http://www.arquitetura.eesc.usp.br/pesquisa/grupos/h abis/biblioteca/digital/artigos/materiais_tecnicas_e_si stemas/Artigo_TERRA\%20BRASIL\%202008_An\%C
3\%A1lise\%20Comparativa\%20Escolha\%20Veda\%C 3\%A7\%C3\%A30\%20Terra\%20Crua\%20para\%20sist ema\%20pilar\%20viga_\%20Maia\%20Ino\%20Shimbo \%20Valle.pdf> Acesso em: 12 Set. 2011.

OLIVEIRA, L. B. - Introdução ao estudo de Adobe: Construção de Alvenaria - Ano 2005. Disponível em:

$<$ http://e-

groups.unb.br/fau/pos_graduacao/paranoa/edicao20 05/adobe.pdf> Acesso em: 12 Set. 2011.

PINTO, T. P. Gestão ambiental de resíduos da construção civil: A experiência do SindusCon-SP. São Paulo: SindusCon - SP, 2005. 48p. Disponível em:

<http://www.gerenciamento.ufba.br/Downloads/Manu al_Residuos_Solidos.pdf>. Acesso em: 14 set. 2011.

RADICCHI, B. Pesquisa sobre cimento promete reduzir emissão de poluentes. 2002. Disponível em:<http://memoria.cnpq.br/noticias/050902.htm> Acesso em 09 set. 2011.

ROSA, S. E. S.; PEIXOTO, G. B. T. O Segmento de Cerâmica para Revestimentos no Brasil. ArtigoBNDES Publicações 2003.16p Disponível em: $<$ http://www.bndes.gov.br/SiteBNDES/bndes/bndes pt/Institucional/Publicacoes/Consulta_Expressa/Tipo/ BNDES_Setorial/200310_12.html. Acesso 16 set 2011>. Acesso em: 12 set. 2011 UFSC, dados - Arquitetura de Terra - Histórico 2004. Disponível em: < http://www.arq.ufsc.br/arq5661/trabalhos 20041/arq_terra/historico.htm > Acesso em: 12 Set. 2011. 